\title{
A Numerical Study on Optimization of Side-by-Side Mooring System of Floating LNG Bunkering Terminal with LNG Carrier in Operation Condition
}

\author{
YunHo Kim, HongGun Sung and SeokKyu Cho \\ Offshore Plant Dept., Korea Research Inst. of Ships \& Ocean Eng., Daejeon 34103, Korea
}

Received: March 16, 2017 / Accepted: March 29, 2017 / Published: May 31, 2017.

\begin{abstract}
In this study, we perform a series of numerical calculations on two vessels in the time domain. One vessel maintains its position using an internal turret and catenary mooring lines, while the other is moored to the former vessel via an STS (ship-to-ship) mooring system. We obtain hydrodynamic forces using the HOBEM (higher-order boundary element method). Then, we determine their coefficients using the convolution function method in the time domain. We model the catenary mooring lines using the finite element method, and the STS mooring lines are treated as linear SPs (springs) with constraints. To optimize the STS system, we conduct parametric studies on STS mooring systems. Finally, we compare the motion and structural responses of the initial and modified configurations.
\end{abstract}

Key words: FLBT (floating LNG bunkering terminal), LNGC (LNG carrier), time-domain analysis, STS mooring system, catenary mooring lines with internal turret.

\section{Introduction}

An FLBT (floating LNG bunkering terminal) is considered as infrastructure that can realize a reduction in LNG fuel received from an LNGC (LNG carrier), or inject LNG fuel into an LNG BS (bunkering shuttle) while it is moored at a work site. It should be able to withstand harsh oceanic environments, which consist mainly of waves, wind, and current. In addition, the LNG transfer process is performed at sea using either a side-by-side or tandem configuration.

Many studies have been performed to analyze the performance of a turret-moored vessel and two moored vessels. For example, Bernitsas and Papoulias [1] performed a study that highlighted the importance of yaw stability on a single-point moored vessel. This work was extended by Rho [2] to two floaters with a

Corresponding author: YunHo Kim, master, senior researcher, research field: ocean engineering. tandem configuration. Arjan and Hielke [3] conducted an optimization study on offshore offloading operation systems, and systematically summarized and analyzed potential offloading systems. Multi-body interaction problems in motion and structural reliabilities have been studied by a number of researchers, such as Koo and Kim [4], Hans et al. [5], Li [6], Hong et al. [7], and Cho [8].

In recent years, there has been increased focus on the development of FLBTs. To this end, it should be evaluated based on its mooring capability and on the STS mooring system. In this study, we perform a parametric study on the STS mooring system in order to optimize it from the perspective of its motion and structural reliabilities.

\section{Simulation Model and Condition}

The schematic view of an FLBT with an LNGC and catenary mooring lines is illustrated in Fig. 1. In addition, the main characteristics of the FLBT and 


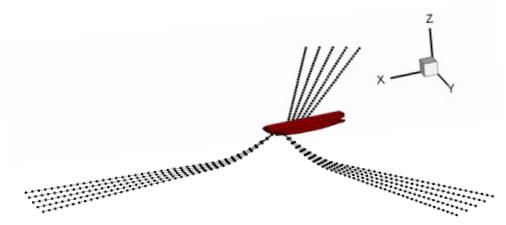

Fig. 1 Configuration of FLBT \& LNGC.

Table 1 Characteristics of FLBT and LNGC.

\begin{tabular}{lll}
\hline Item & FLBT & LNGC \\
\hline Loa $[\mathrm{m}]$ & 355.6 & 294.0 \\
B [m] & 60.0 & 45.5 \\
D [m] & 32.7 & 26.0 \\
T [m] & 13.5 & 11.6 \\
L.C.G [m] & -0.695 & 1.270 \\
L.C.B. [m] & -0.695 & 1.270 \\
Disp. [ton] & $2.393 \mathrm{e} 05$ & $1.147 \mathrm{e} 05$ \\
GMT [m] & 13.509 & 19.83 \\
\hline
\end{tabular}

LNGC are listed in Table 1. Where, Loa is the overall length, $\mathrm{B}$ is the breadth, $\mathrm{D}$ is the depth, and $\mathrm{T}$ is the draft. The LCG (longitudinal center of gravity) is from the mid-ship section, and the LCB (longitudinal center of buoyancy) is from the mid-ship section. GMT is the transverse metacentric height.

$3 \times 5$ catenary mooring lines are installed at an FLBT internal turret. The center of the turret is $\mathrm{X}=$ $+103.4 \mathrm{~m}$ from the mid-ship section and $\mathrm{Y}=0.0 \mathrm{~m}$ from the centerline. The turret radius is $7.5 \mathrm{~m}$. The interval of each mooring line in one cluster is $3.0^{\circ}$, and the angle subtended from the center of each cluster is $120^{\circ}$. The radius of the mooring lines is
$1,000 \mathrm{~m}$ from the turret center to the anchor points, and the length of one mooring line is $1,012 \mathrm{~m}$.

The planar configuration of two floaters is illustrated in Fig. 2. The FLBT and LNGC are connected using five MRs (mooring ropes), two mooring SPs (springs), and four FDs (fenders). Three types of STS mooring system are modeled as linear SPs, while their performance constraints are different. MRs are only activated when they are elongated, and FDs are only activated when they are compressed. Mooring SPs do not have any constraints in the direction. Details of STS mooring systems are listed in Table 2. These values were obtained from KORDI (2011), which is a project that addressed a similar problem involving side-by-side moored FSRU and LNGC.

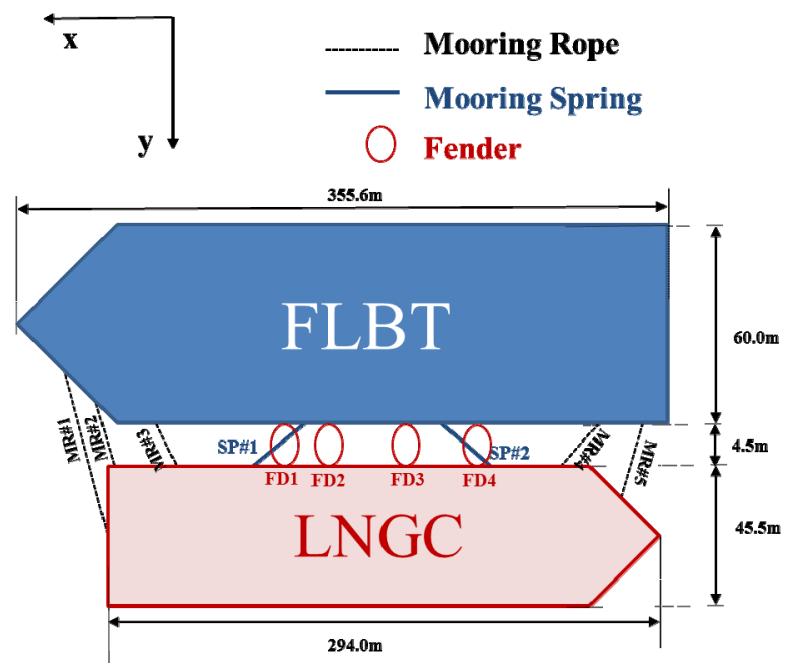

Fig. 2 Schematic view of STS mooring system.

Table 2 Characteristics of STS mooring system and installation points.

\begin{tabular}{lllllllll}
\hline \multirow{2}{*}{ STS } & $\mathrm{L}$ & $\mathrm{K}$ & \multicolumn{3}{c}{ FLBT } & \multicolumn{3}{c}{ LNGC } \\
\cline { 5 - 9 } & {$[\mathrm{m}]$} & {$[\mathrm{kN} / \mathrm{m}]$} & $\mathrm{X}[\mathrm{m}]$ & $\mathrm{Y}[\mathrm{m}]$ & $\mathrm{Z}[\mathrm{m}]$ & $\mathrm{X}[\mathrm{m}]$ & $\mathrm{Y}[\mathrm{m}]$ & $\mathrm{Z}[\mathrm{m}]$ \\
\hline MR1 & 40.57 & $1,031.4$ & 159.48 & 18.89 & 19.20 & -137.6 & 4.55 & 14.40 \\
MR2 & 28.06 & 493.6 & 146.44 & 25.55 & 19.20 & -130.5 & 9.10 & 14.40 \\
MR3 & 19.40 & 512.6 & 131.95 & 30.0 & 19.20 & -116.4 & 16.68 & 14.40 \\
MR4 & 26.41 & 549.6 & -154.8 & 30.0 & 19.20 & 134.38 & 11.23 & 14.40 \\
MR5 & 38.17 & 998.7 & -161.7 & 30.0 & 19.20 & 141.10 & -4.55 & 14.40 \\
SP1 & 58.98 & 420.7 & 29.60 & 30.0 & 19.20 & -88.19 & 22.75 & 14.40 \\
SP2 & 70.42 & 461.1 & -20.59 & 30.0 & 19.20 & 90.71 & 22.75 & 14.40 \\
FD1 & 4.50 & $1,117.5$ & 51.02 & 30.0 & 0.00 & -51.02 & -30.0 & 0.00 \\
FD2 & 4.50 & $1,117.5$ & 17.90 & 30.0 & 0.00 & -17.90 & -30.0 & 0.00 \\
FD3 & 4.50 & $1,117.5$ & -14.90 & 30.0 & 0.00 & 14.90 & -30.0 & 0.00 \\
FD4 & 4.50 & $1,117.5$ & -47.74 & 30.0 & 0.00 & 47.74 & -30.0 & 0.00
\end{tabular}


The operating condition for the LNG transfer process is as below. This condition is achieved from the target location near the Pusan port, which is one of the potential locations for the operation of the FLBT.

- Wave: JONSWAP spectrum

$\mathrm{Hs}=2.1 \mathrm{~m}, \mathrm{Tp}=6.02 \mathrm{~s}, \gamma=3.3$, Heading $=180^{\circ}$

- Wind: $16 \mathrm{~m} / \mathrm{s}$

- Current: $2.1 \mathrm{~m} / \mathrm{s}$

In this study, we considered only the wave load, while current and wind loads will be considered in future study. In addition, we analyzed only the head sea condition with the assumption that a turret-moored vessel weathervanes to the minimum environmental heading angle. The total simulation time is $12,600 \mathrm{~s}$ with a ramp function of $1,800 \mathrm{~s}$.

\section{Numerical Method}

In order to obtain the hydrodynamic coefficients, we utilized the Wave Green Function method based on the potential theory. The discretized numerical shape is represented by 9-node bi-quadratic elements. By adopting higher-order schemes, it is possible to obtain the quadratic distribution of the physical values on each element. In addition, the convergence speeds of second-order quantities are significantly increased [9].

We modeled the behavior of the mooring lines using the finite-element method, and the equation takes the following form:

$$
[M(u)]\{\ddot{u}\}+[C(u)]\{u\}+[K(u)]\{u\}=\{f(\xi)\}+\{f(\dot{u}, \ddot{u})\}
$$

where, $u$ is the displacement vector, and $[M(u)],[C(u)]$, and $[K(u)]$ are the geometrically nonlinear matrices for inertia, damping and stiffness, respectively. $\{f(\xi)\}$ is the external force vector due to the floater's motion, while $\{f(\dot{u}, \ddot{u})\}$ is the Morison force from the external waves. In the FE model, we applied the minimum-energy principle, and adopted the Lagrange multiplier method. The fairlead motion acts as a boundary condition. Details were reported by Kim et al. [10].

Three types of connectors were modeled as linear SPs with some restrictions based on unstretched lengths. The coupled solution can be achieved using solving floaters, mooring lines, and STS systems. We utilized the Newmark- $\beta$ method for time marching.

\section{Simulation Results}

\subsection{Initial Design Simulation}

Using the higher-order boundary element method, we calculated the motion RAO (response amplitude operator), and compared it with experimental data, as shown in Figs. 3-5. The natural frequency of the heave was $0.5 \mathrm{rad} / \mathrm{s}$, and that of the pitch was $0.38 \mathrm{rad} / \mathrm{s}$, which are shown clearly in both sets of data. As both results were similar, this numerical scheme can be regarded as a reliable approach.

Fig. 6 shows the motion time series of the center of the FLBT. The vertical motions, namely the heave, roll, and pitch, were relatively stable, and did not exceed $\pm 0.1 \mathrm{~m}$ or $\pm 0.5^{\circ}$. On the other hand, the horizontal motions, surge, sway, and yaw departed significantly from the initial position. In particular, the LNGC drifted much further than the FLBT because of the absence of its own mooring system.

Fig. 7 shows the tension values of the mooring lines that were installed on the FLBT. As seen in Fig. 7, the FLBT's own mooring system was somewhat reliable. The total maximum tension did not exceed 2,500 kN, while the MBL (minimum breaking load) was $15,964.84 \mathrm{kN}$. It is considered that this mooring system can withstand the operating conditions.

The tension values of the MRs, mooring SPs, and FDs are shown in Figs. 8-10. Two of the STS mooring systems had length constraints, MRs, and FDs, and their tension values showed peaky signals, while the tension of mooring SPs showed harmonic signals. Peaks of STS mooring tensions were gathered and analyzed statistically. 

Bunkering Terminal with LNG Carrier in Operation Condition

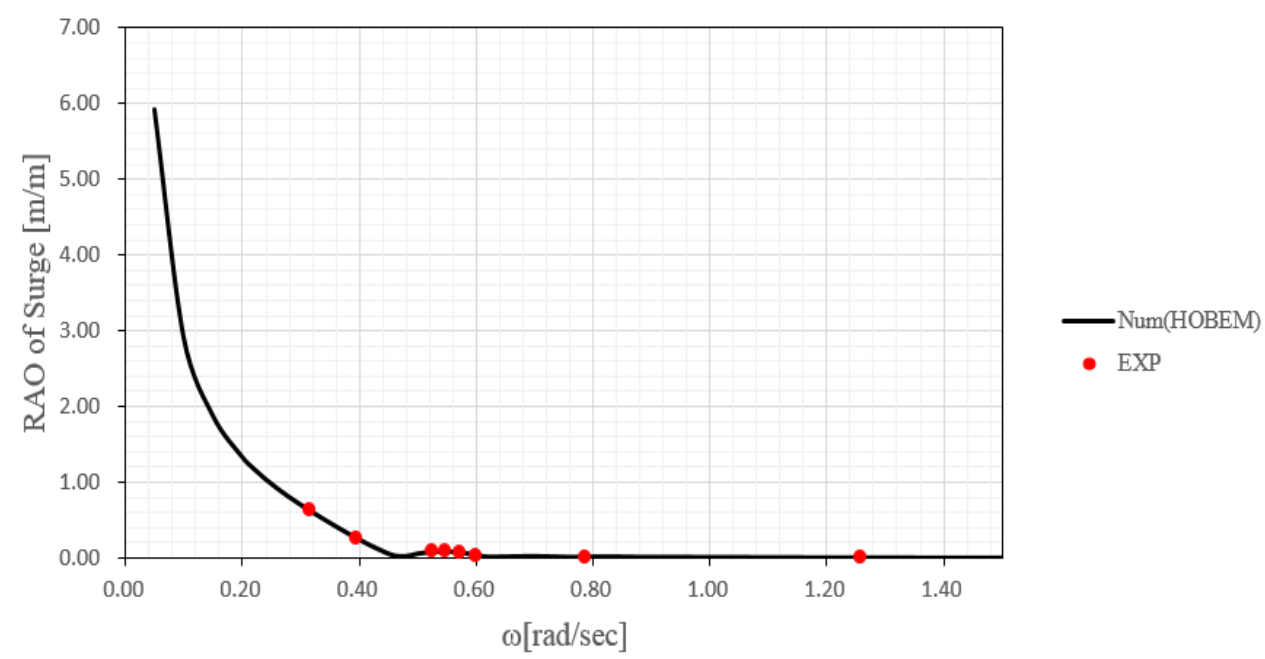

Fig. 3 Surge motion RAO.

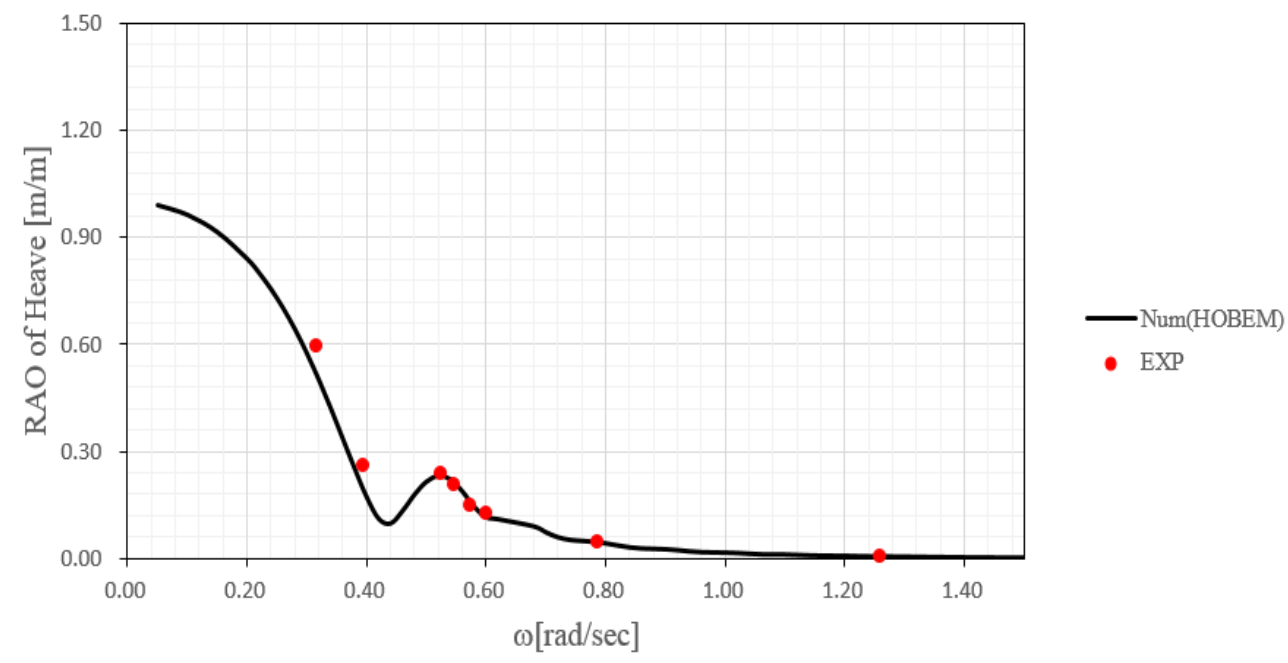

Fig. 4 Heave motion RAO.

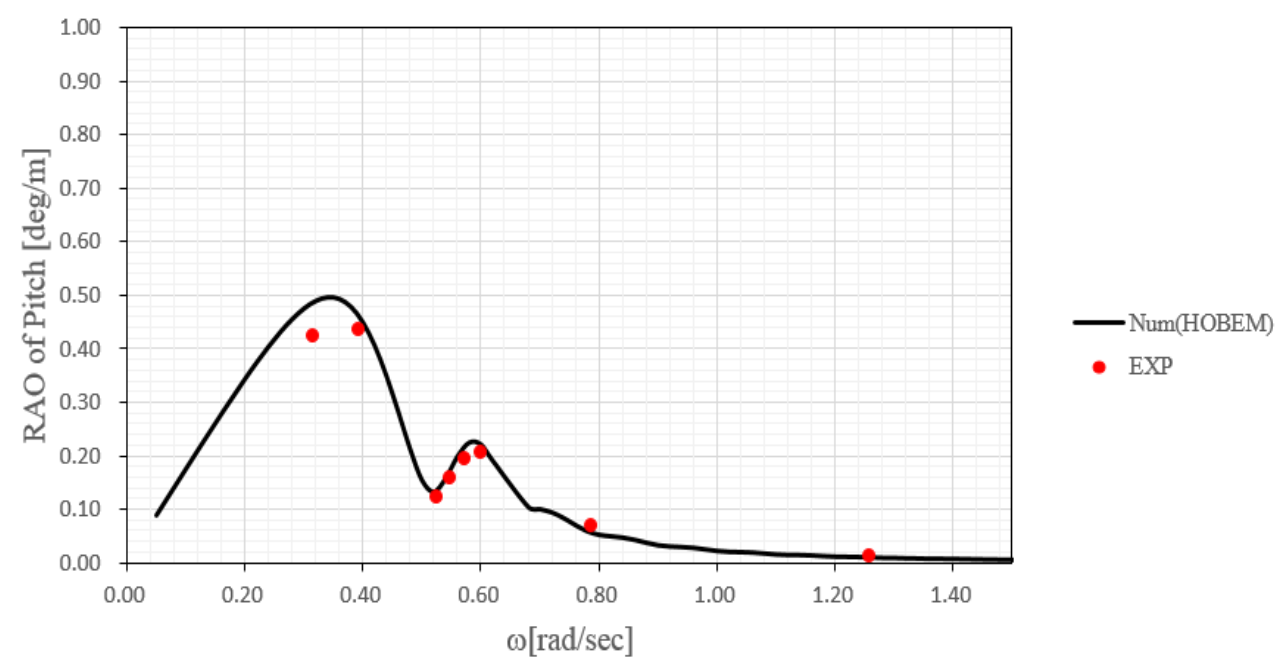

Fig. 5 Pitch motion RAO. 
A Numerical Study on Optimization of Side-by-Side Mooring System of Floating LNG Bunkering Terminal with LNG Carrier in Operation Condition
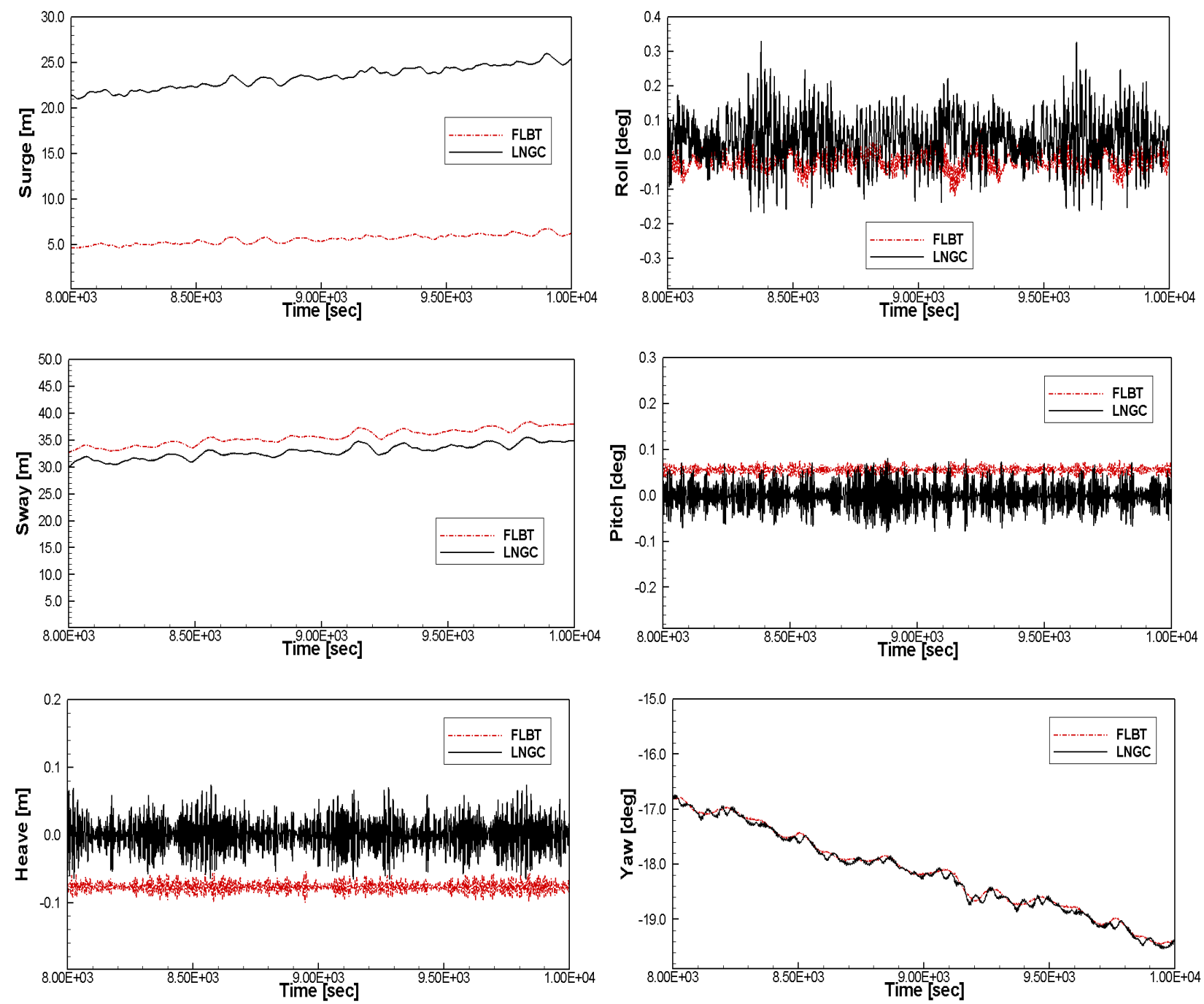

Fig. 6 Time series of FLBT and LNGC 6 DoF motions.
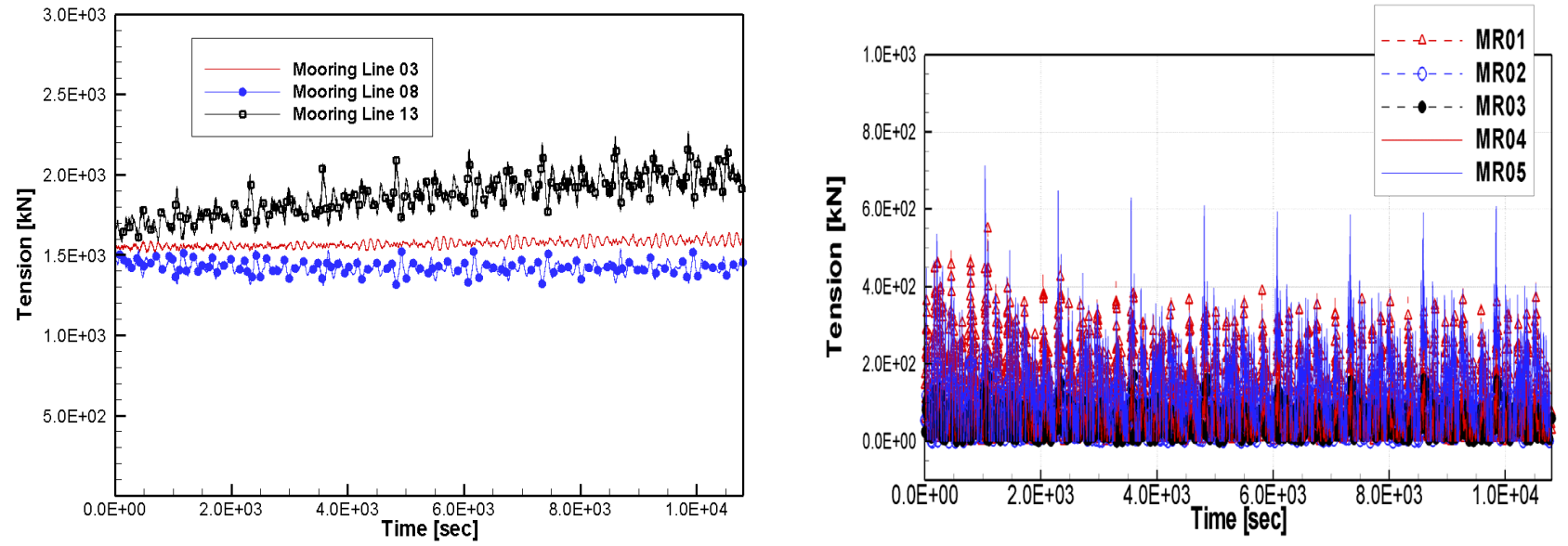

Fig. 7 Time series of tensions of mooring line \#03, \#08 and \#15.

Fig. 8 Tension series of MRs. 


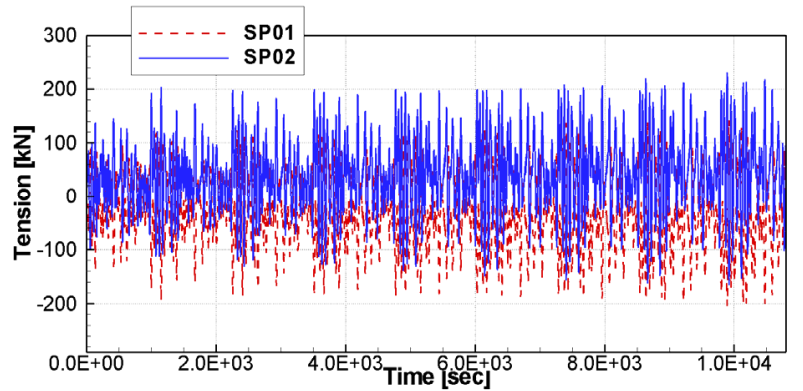

Fig. 9 Tension series of mooring SPs.

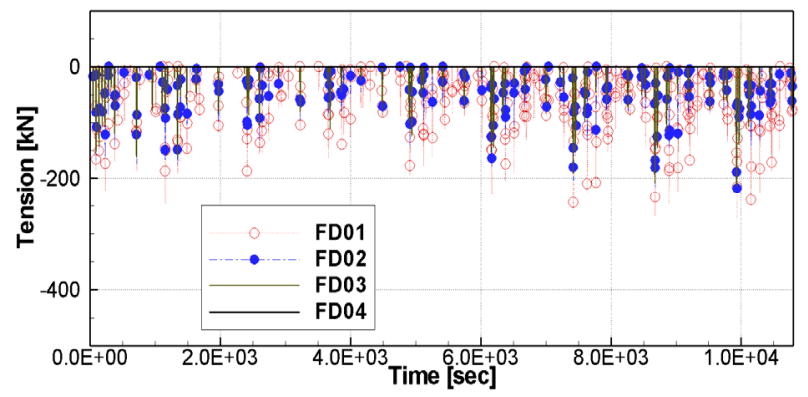

Fig. 10 Tension series of FDs.

\subsection{Parametric Study of STS Mooring Systems}

The STS mooring systems utilized in this study were those used in a similar project carried out previously [11]. They were optimized by performing parametric studies to determine the stiffness of each mooring device. In each case, the initial values were changed from $10 \%$ to $300 \%$, and the cases were numerically calculated.

\subsubsection{Variation in MR Stiffness}

First, we varied the stiffness of the MRs. Table 3 also summarizes the significant motion heights of the vertical motions of the two vessels. As the variation in the motion responses was almost negligible, STS mooring systems need to be analyzed from the perspective of structural responses.

Fig. 11 shows the means of the STS mooring systems' tension peaks as the stiffness of the MRs varied. The means of the mooring SPs' tension peaks decreased as the mooring-rope stiffness increased in mooring SPs, while those of the mooring-ropes' tension peaks and FDs' tension peaks were relatively unchanged. In addition, in all cases, fender \#4 was not tense, and it could be eliminated. The maximum tension peaks observed during the calculation time are illustrated in Fig. 12. The maximum tension peaks of the MRs were observed to increase dramatically, while those of the others generally decreased. The $50 \%$ mooring-rope stiffness case had a minimum tension peak, which would be adjusted to the modified configuration.

\subsubsection{Variation in Mooring SP Stiffness}

We performed the same parametric study on mooring SPs, and the maximum tensions of STS mooring devices are shown in Fig. 13. MR \#01 and \#05, which were installed at the front and at the end of FLBT accordingly, were tensed mostly in the small-stiffness region, while the maximum tension peaks of mooring SPs were as crucial as those of MR \#01 and \#05. As choosing the case of one minimum tension peak in all STS systems, $75 \%$ mooring spring stiffness case would be utilized in the modified configuration.

\subsubsection{Variation in FD Stiffness}

As the stiffness of the FDs increased, the maximum

Table 3 Significant motion heights of two vessels' vertical motions with mooring-rope variation.

\begin{tabular}{lllllll}
\hline \multirow{2}{*}{$\begin{array}{l}\text { Stiffness of } \\
\text { MR }\end{array}$} & \multicolumn{3}{c}{ FLBT } & \multicolumn{2}{c}{ LNGC } \\
\cline { 2 - 7 } & Heave [m] & $\begin{array}{l}\text { Roll } \\
{[\mathrm{deg}]}\end{array}$ & $\begin{array}{l}\text { Pitch } \\
{[\mathrm{deg}]}\end{array}$ & Heave [m] & $\begin{array}{l}\text { Roll } \\
{[\mathrm{deg}]}\end{array}$ & $\begin{array}{l}\text { Pitch } \\
{[\mathrm{deg}]}\end{array}$ \\
\hline $10 \%$ & 0.0279 & 0.07828 & 0.03055 & 0.08644 & 0.23919 & 0.11469 \\
$25 \%$ & 0.02786 & 0.07666 & 0.03054 & 0.08639 & 0.24305 & 0.11448 \\
$50 \%$ & 0.02782 & 0.07798 & 0.03053 & 0.0862 & 0.23384 & 0.11412 \\
$75 \%$ & 0.02785 & 0.07796 & 0.03045 & 0.08612 & 0.2426 & 0.11375 \\
$100 \%$ & 0.02782 & 0.07895 & 0.03041 & 0.08598 & 0.24977 & 0.11329 \\
$130 \%$ & 0.02782 & 0.07944 & 0.03037 & 0.08586 & 0.24421 & 0.1129 \\
$150 \%$ & 0.02781 & 0.08136 & 0.03033 & 0.08578 & 0.25031 & 0.11257 \\
$200 \%$ & 0.02781 & 0.08315 & 0.03024 & 0.08566 & 0.24685 & 0.1121 \\
$300 \%$ & 0.02773 & 0.09097 & 0.03014 & 0.08547 & 0.28538 & 0.11125 \\
\hline
\end{tabular}



Bunkering Terminal with LNG Carrier in Operation Condition

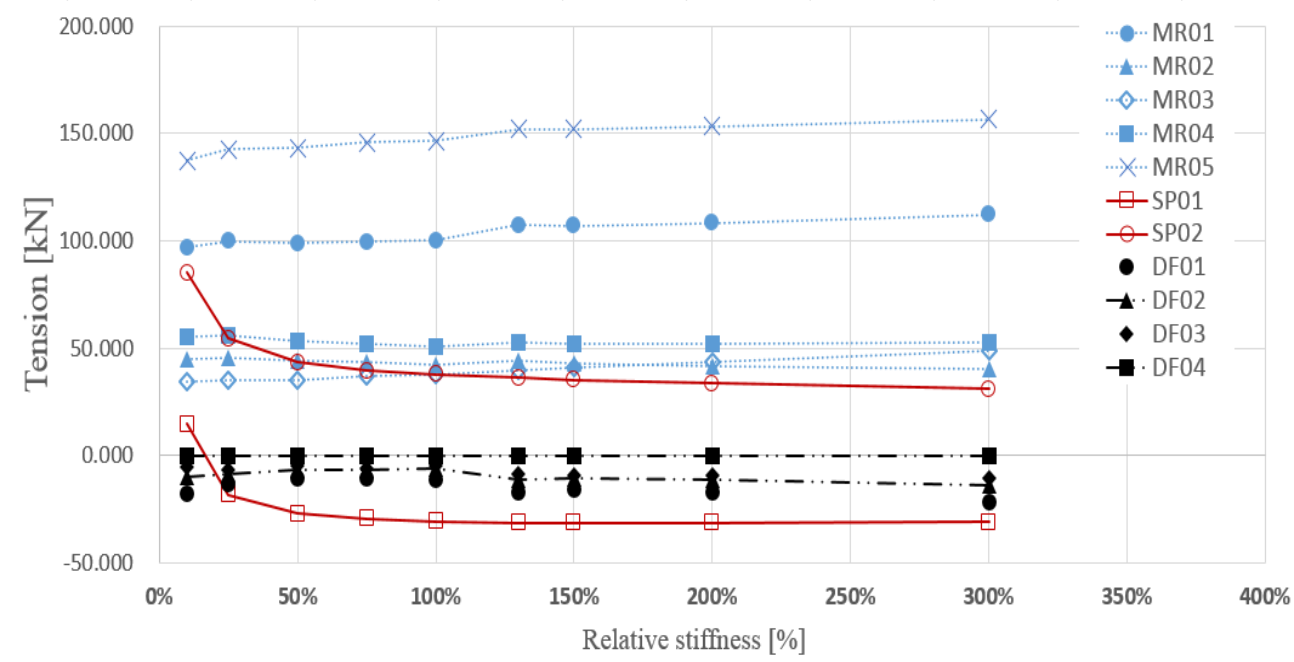

Fig. 11 Mean of STS mooring system's tension peaks with MR variation.

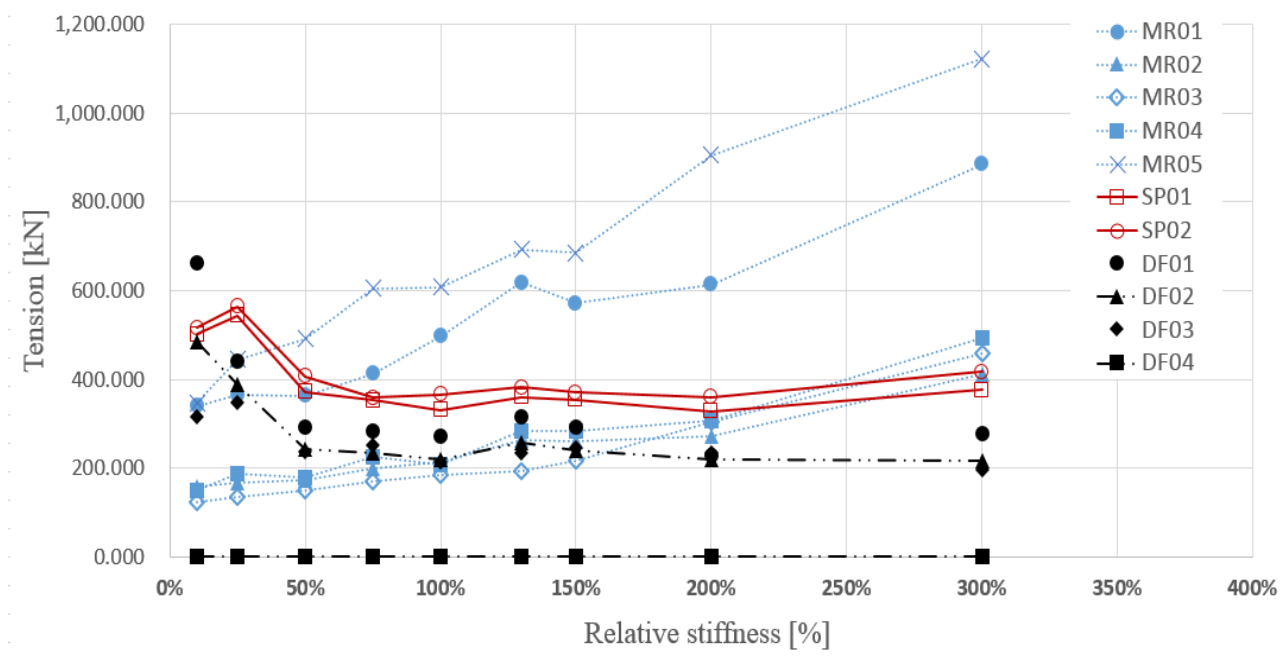

Fig. 12 Maximum of STS mooring system's tension peaks with MR stiffness variation.

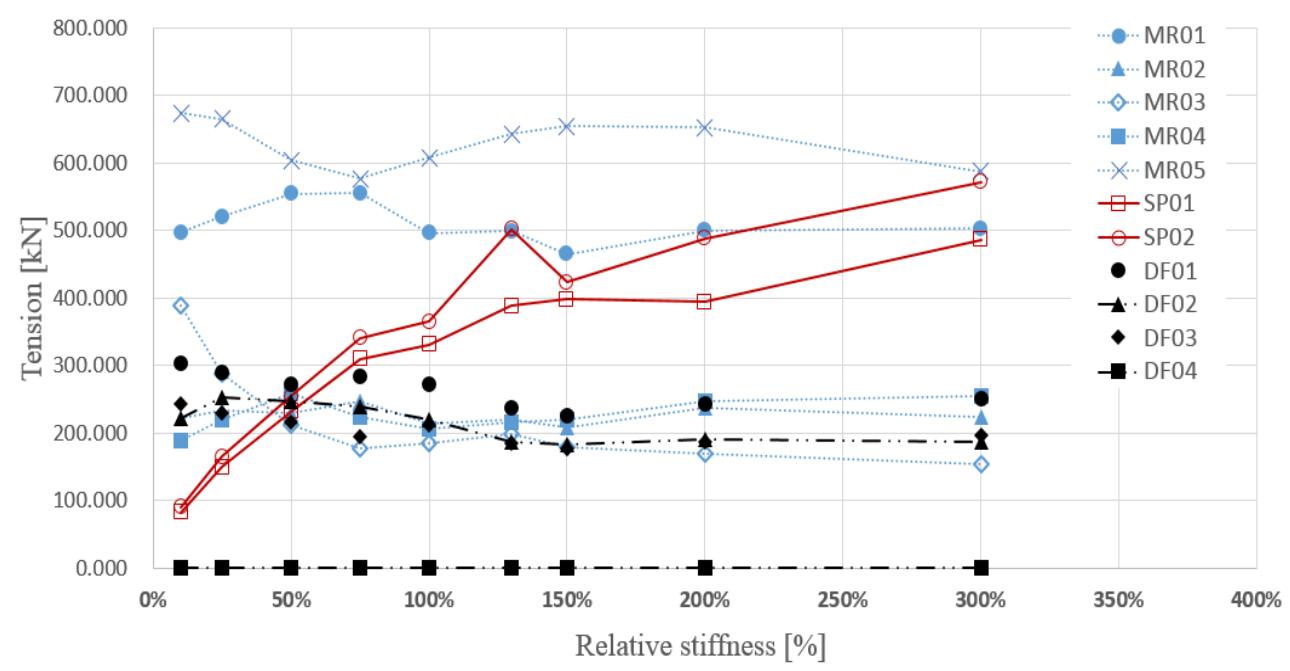

Fig. 13 Maximum of STS mooring system's tension peaks with mooring SP variation. 


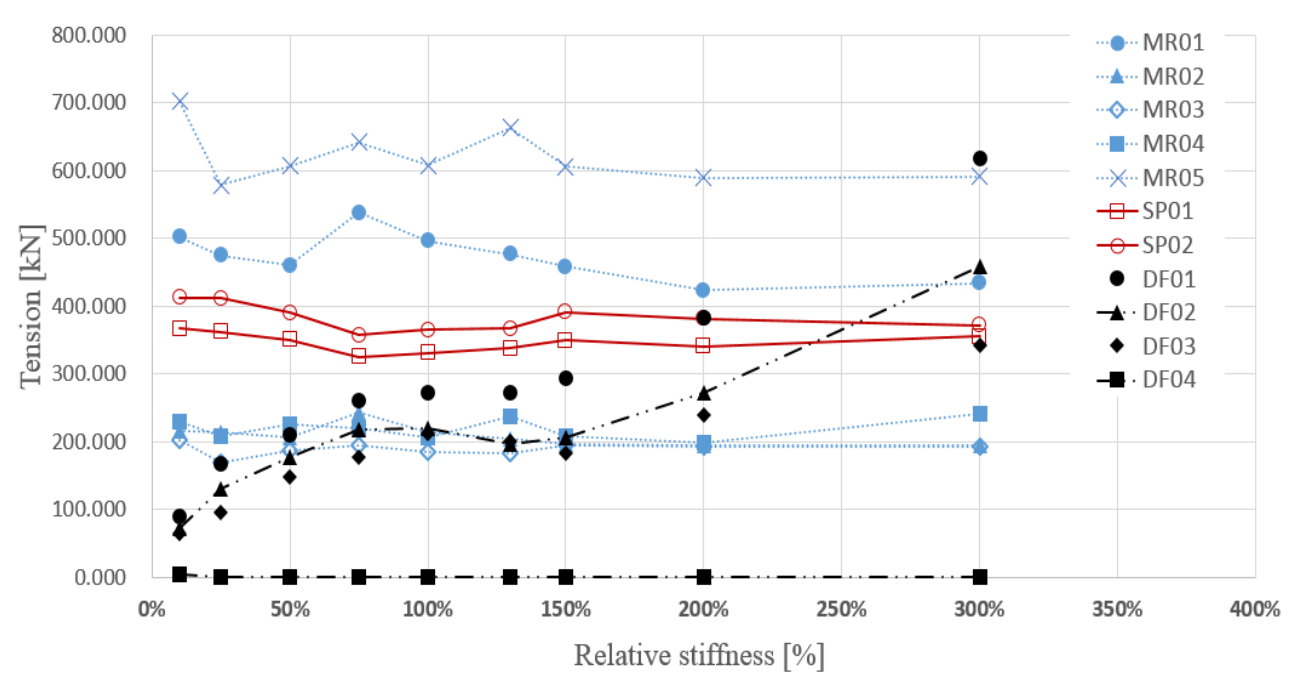

Fig. 14 Maximum of STS mooring system's tension peaks with fender variation.

tension peaks of the FDs significantly increased, as shown in Fig. 14. Using the same methodology involving MRs and mooring SPs, we decided to choose the case with an FD stiffness of $25 \%$.

\subsection{Modified Design Simulation}

We conducted parametric studies on the device stiffness of STS mooring devices, and for the FLBT-LBNG STS mooring system. We obtained stiffness values of $50 \%, 75 \%$, and $25 \%$ for the MRs, mooring SPs, and FDs, respectively. We conducted a time-domain analysis using the modified configuration. The time series of the tensions on MR
\#1, SP \#1, and DF \#01 are illustrated in Figs. 15-17, respectively.

Finally, Table 4 shows the statistical values of the initial and modified STS mooring systems. For two configurations, the mean values were somewhat similar, while the maximum values were different. Even MR \#04 and SP \#01 showed larger maximum tension peaks, while other devices showed lower maximum tension peaks. In particular, we observe a reduction of almost $35 \%$ in $\mathrm{FD} \# 03$. As the motion responses in both configurations were quite similar, the modified configuration had a significant advantage in terms of the structural responses.

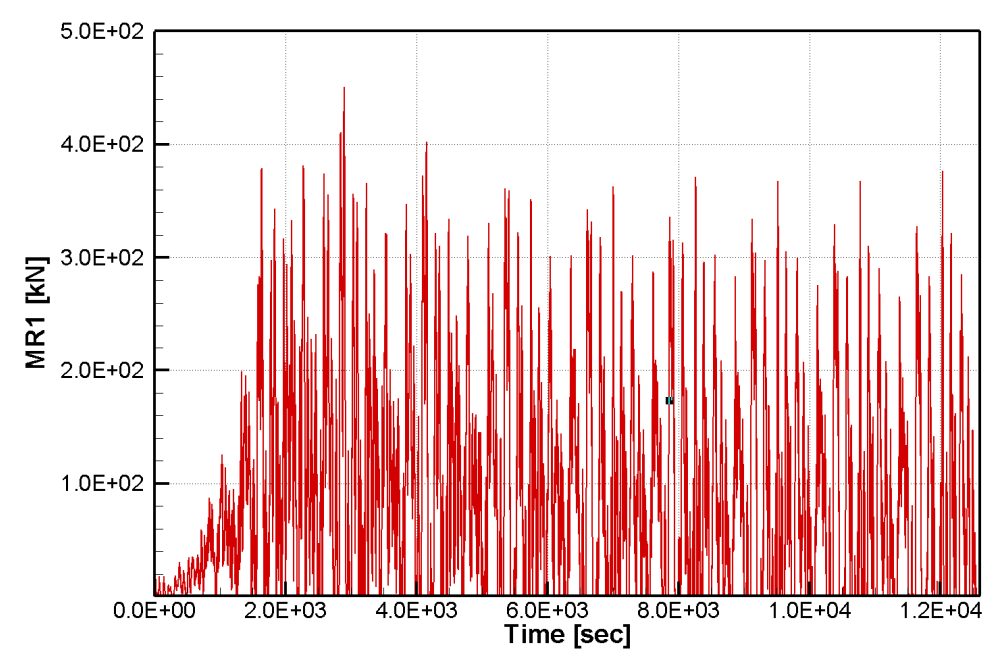

Fig. 15 Tension at MR \#1 with the modified STS system. 

Bunkering Terminal with LNG Carrier in Operation Condition

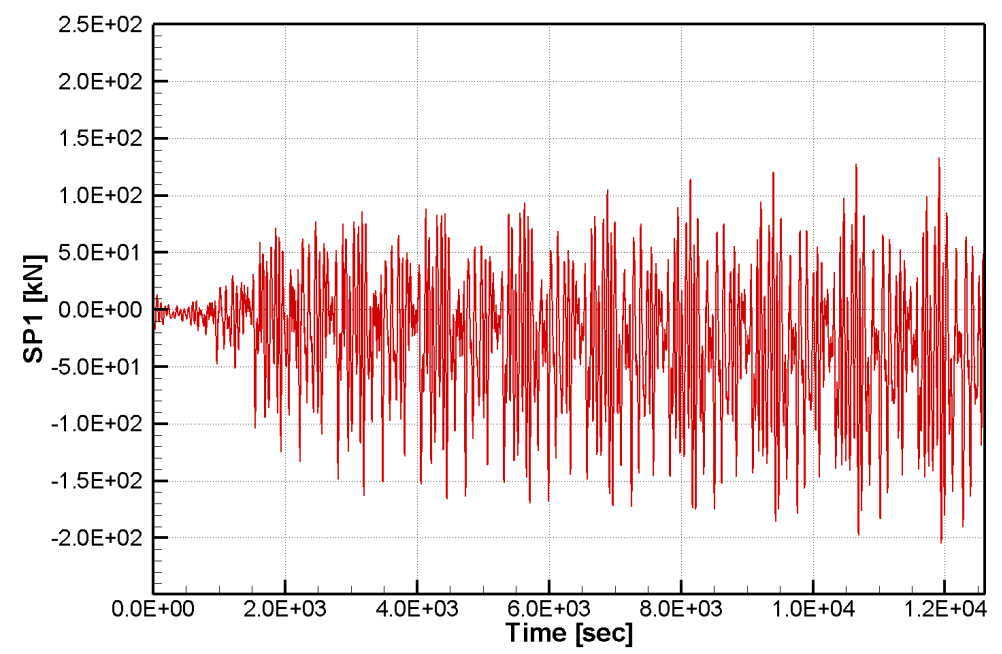

Fig. 16 Tension at mooring SP \#1 with the modified STS system.

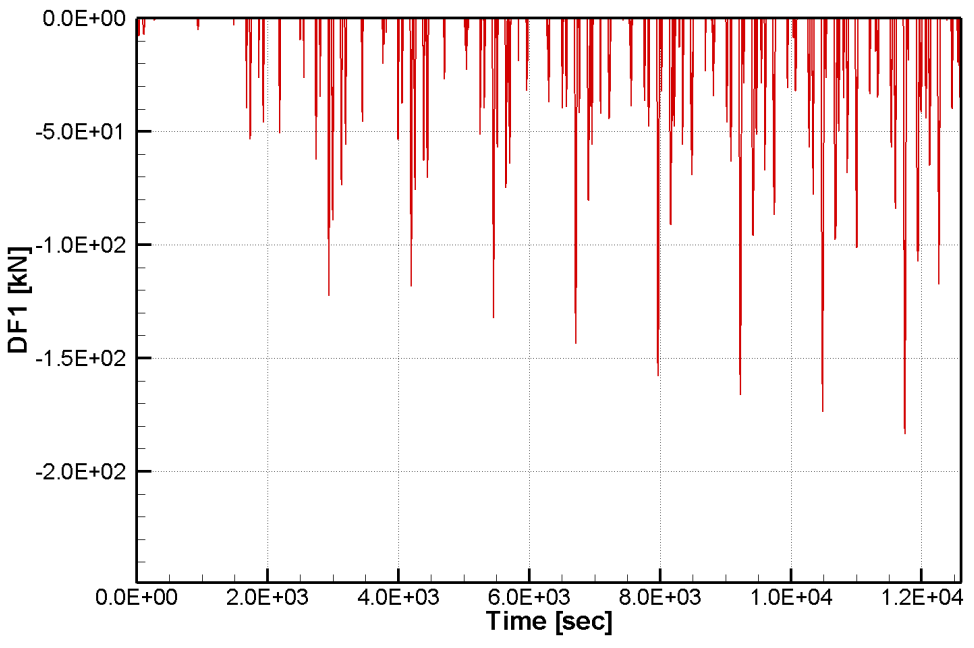

Fig. 17 Tension at fender \#1 with the modified STS system.

Table 4 Comparison of statistical values of the initial system and the modified system.

\begin{tabular}{lllllll}
\hline \multirow{2}{*}{ STS mooring } & \multicolumn{3}{c}{ Mean value } & \multicolumn{3}{c}{ Maximum value } \\
\cline { 2 - 6 } & $\begin{array}{l}\text { Initial system } \\
{[\mathrm{kN}]}\end{array}$ & $\begin{array}{l}\text { Modified system } \\
{[\mathrm{kN}]}\end{array}$ & $\begin{array}{l}\text { Ratio } \\
{[\%]}\end{array}$ & $\begin{array}{l}\text { Initial system } \\
{[\mathrm{kN}]}\end{array}$ & $\begin{array}{l}\text { Modified system } \\
{[\mathrm{kN}]}\end{array}$ & $\begin{array}{l}\text { Ratio } \\
{[\%]}\end{array}$ \\
\hline MR 01 & 100.154 & 96.483 & 96.335 & 496.283 & 450.542 & 90.783 \\
MR 02 & 42.234 & 43.300 & 102.526 & 214.320 & 206.433 & 96.320 \\
MR 03 & 37.424 & 36.430 & 97.343 & 185.370 & 150.518 & 81.199 \\
MR 04 & 50.408 & 51.706 & 102.576 & 206.992 & 215.871 & 104.289 \\
MR 05 & 146.270 & 143.358 & 98.010 & 608.088 & 574.637 & 94.499 \\
SP 01 & -30.766 & -29.112 & 94.625 & 331.218 & 337.683 & 101.952 \\
SP 02 & -37.746 & 40.958 & 108.511 & 365.337 & 351.127 & 96.111 \\
FD 01 & -11.346 & -8.069 & 71.112 & 272.835 & 183.429 & 67.231 \\
FD 02 & -6.201 & -6.247 & 100.743 & 219.730 & 159.944 & 72.791 \\
FD 03 & -4.731 & -5.304 & 112.105 & 212.613 & 139.365 & 65.549 \\
FD 04 & 0.000 & 0.000 & - & 0.000 & 0.000 & - \\
\hline
\end{tabular}




\section{Conclusions}

In this study, we conducted a series of time-domain analyses on FLBT and LNGC using FLBT's mooring lines and STS mooring systems. The following conclusions were made:

(1) The motion responses induced by a wave's first-order components are relatively stable. While those induced by a wave's second-order components are large, the equilibrium positions in the planar motion, surge, sway, and yaw, are separate from the original position.

(2) The motion responses are insensitive to variations in the stiffness of the STS mooring system. The tension peaks of each system are varied by varying the STS mooring system stiffness.

(3) From parametric studies on the stiffness of STS mooring systems, for the FLBT-LBNG STS mooring system, we chose stiffness values of $50 \%, 75 \%$, and $25 \%$ for the MRs, mooring SPs, and FDs, respectively.

(4) From the perspective of the structural reliability, the modified configuration shows a significant reduction in the maximum tensions at the FDs, while those at the mooring lines and mooring SPs are relatively similar to the initial design results that were obtained.

(5) These results will be utilized to identify suitable mooring devices in real situations. In addition, in future, we will perform studies that consider a wide variety of environmental conditions.

\section{Acknowledgements}

This work was supported by the Ministry of Oceans and Fisheries, Korea, "Development of Technology for Floating Offshore LNG Bunkering System (PMS3481)" and KRISO Internal Research Program,
"Development of Basic Operation Technique for Running of the Deepsea Offshore Engineering Basin (PES9080)". All support is gratefully acknowledged.

\section{References}

[1] Bernitsas, M. M., and Papoulias, F. A. 1986. "Stability of Single Point Mooring Systems." Applied Ocean Research 8 (1): 49-58.

[2] Rho, J. B. 2006. "Global Performance Analysis of Multiple Offshore Structures Connected with Mooring Lines and Fluid Transfer Line." Ph.D. thesis, Seoul National University.

[3] Arjan, V., and Hielke, B. 2010. "Numerical Simulations to Optimize Offshore Offloading Operations." In Proceedings of the Offshore Technology Conference (OTC).

[4] Koo, B. J., and Kim, M. H. 2005. "Hydrodynamic Interactions and Relative Motions of Two Floating Platforms with Mooring Lines in Side-by-Side Offloading Operation." Applied Ocean Research 27: 292-310.

[5] Hans, F. H., Stefan, C., Erik, D. C., and Jens, K. 2009. "Multi Vessel Interaction in Shallow Water." In Proceedings of the OMAE, 147-54.

[6] Li, L. 2009. "Two-Ship Operating in Close Proximity in Shallow Water Rough Sea.” In Proceedings of the ISOPE, 654-61.

[7] Hong, Y. P., Wade, Y., Choi, Y. H., and Kim, S. E. 2009. "An Experimental and Numerical Study on the Motion Characteristics of Side-by-Side Moored LNG-FPSO and LNG Carrier." In Proceedings of the ISOPE, 172-9.

[8] Cho, S. K. 2012. "A Study on the Motion Behaviour of Side-by-Side Moored Two Floaters Including Sloshing Effects." Ph.D. thesis, Seoul National University.

[9] Hong, S. Y., Kim, J. H., Cho, S. K., Choi, Y. R., and Kim, Y. S. 2005. "Numerical and Experimental Study on Hydrodynamic Interactions of Side-by-Side Moored Multiple Vessels." Ocean Engineering 32 (7): 783-801.

[10] Kim, B. W., Sung, H. G., Hong, S. Y., and Jung, H. J. 2010. "Finite Element Nonlinear Analysis for Catenary Structure Considering Elastic Deformation.” J. Computer Modeling in Eng. 63 (1): 29-45.

[11] KORDI. 2011. Core Methodologies for Design of LNG FSRU. First Phase Report. 